\title{
PERAN KEPALA SEKOLAH DAN IKLIM ORGANISASI DALAM PENINGKATAN KINERJA GURU SEKOLAH DASAR
}

\author{
Patno $^{1}$ \\ ${ }^{1}$ Sekolah Dasar Negeri Anjatan I, Komplek Alun-alun Kecamatan Anjatan, \\ patno76@gmail.com
}

\begin{abstract}
ABSTRAK
Tujuan Penelitian ini untuk mengetahui: (1) pengaruh peran kepala sekolah terhadap peningkatan kinerja guru Sekolah Dasar (SD) di Kabupaten Indramayu; (2) pengaruh iklim Organisasi terhadap kinerja guru Sekolah Dasar di Kabupaten Indramayu; (3) pengaruh peran kepala sekolah dan iklim organisasi terhadap kinerja guru Sekolah Dasar (SD) di Kabupaten Indramayu. Guna mengetahui tujuan penelitian tersebut maka menggunakan rancangan penelitian deskriptif korelasional. Penelitian ini dilaksanakan di sembilan sekolah dasar yang ada di gugus II di UPTD Pendidikan Kecamatan Anjatan dengan jumlah pupulasi sebanyak 79 orang. Sampel diambil secara random proporsional. Pengumpulan data dalam penelitian ini menggunakan kuisioner atau angket sebagai instrumen. Hasil penelitian menunjukkan bahwa: (1) terdapat kontribusi pengaruh peran kepala sekolah terhadap kinerja guru SD Negeri pada Gugus II di UPTD Pendidikan Kecamatan Anjatan Kabupaten Indramayu tergolong signifikan yakni sebesar 18,3 \%; (2) tingkat iklim organisasi termasuk kategori sedang 28,8\%, (3) pengaruh peran kepala sekolah dan iklim organisasi secara bersama-sama terhadap kinerja guru sebesar $34,4 \%$; (4) terdapat hubungan yang signifikan antara peran kepala sekolah dan iklim dengan kinerja guru; (5) terdapat hubungan yang signifikan antara iklim organisasi dengan kinerja guru; (6) terdapat hubungan signifikan antara peran kepala sekolah dan iklim organisasi.
\end{abstract}

\section{Kata kunci: Peran Kepala Sekolah, Iklim Organisasi, Kinerja Guru.}

\section{PENDAHULUAN}

Peningkatan mutu pendidikan ditentukan oleh kesiapan sumber daya manusia yang terlibat dalam proses pendidikan. Guru merupakan salah satu faktor penentu tinggi rendahnya mutu hasil pendidikan mempunyai posisi strategis maka setiap usaha peningkatan mutu pendidikan perlu memberikan perhatian besar kepada peningkatan guru baik dalam segi jumlah maupun mutunya. Sukses dan tidaknya pendidikan dan pembelajaran disekolah sangat dipengaruhi oleh kinerja guru sebagai orang yang berhadapan langsung dengan peserta didik.

Guru adalah figur yang menempati posisi penting dan memegang peran dalam pendidikan. Ketika semua orang mempersoalkan masalah dunia pendidikan figur guru mesti terlibat dalam agenda pembicaraan terutama yang menyangkut persoalan pendidikan formal di sekolah. Pendidik atau guru merupakan tenaga profesional yang bertugas merencanakan dan melaksanakan proses pembelajaran, menilai hasil pembelajaran, melakukan pembimbingan dan pelatihan, serta melakukan penelitian dan pengabdian kepada masyarakat, terutama bagi pendidik pada perguruan tinggi. Hal tersebut tidak dapat disangkal kerana 
lembaga pendidikan adalah dunia kehidupan guru. Sebagai besar waktu guru ada di sekolah, sisanya ada di rumah dan di masyarakat (Djamarah, 2002).

Dari data capaian prestasi tertinggi siswa di sekolah dasar negeri pada gugus II UPTD Pendidikan Kecamatan Anjatan baik prestasi bidang akademik maupun non akademik siswa baru mampu bicara pada level tingkat kecamatan, itupun hanya sebagian kecilnya saja. Hasil capaian prestasi siswa dapat dilihatdalam tabeldibawah ini:

Tabel 1 Daftar Capaian Prestasi Tertinggi SD di Gugus II.

\begin{tabular}{|c|c|c|c|}
\hline No & Nama SD & $\begin{array}{c}\text { Capaian Prestasi } \\
\text { Bidang Akademik }\end{array}$ & $\begin{array}{c}\text { Capaian Prestasi Bidang } \\
\text { Non Akademik }\end{array}$ \\
\hline 1. & SDN Anjatan Baru I & $\begin{array}{l}\text { - Juara II Lomba } \\
\text { Calistung Tingkat } \\
\text { GugusII } \\
\text { - Juara II Lomba } \\
\text { MIPA Tingkat Gugus }\end{array}$ & - Juara I \\
\hline 2. & SDN Anjatan Baru II & $\begin{array}{l}\text { - Juara III Lomba } \\
\text { Calistung Tingkat } \\
\text { Gugus }\end{array}$ & $\begin{array}{l}\text { - Juara I O2SN Tingkat } \\
\text { Gugus Cabang Sepak } \\
\text { Bola }\end{array}$ \\
\hline 3. & SDN Anjatan Baru III & 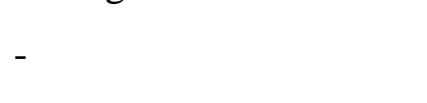 & $\begin{array}{l}\text { - Juara I O2SN Cabang } \\
\text { Bulu Tangkis }\end{array}$ \\
\hline 4. & SDN Anjatan Baru IV & - & $\begin{array}{l}\text { - Juara I O2SN Cabang } \\
\text { Atletik }\end{array}$ \\
\hline 5. & SDN Kopyah I & $\begin{array}{l}\text { - Juara II Lomba Siswa } \\
\text { Berprestasi } \\
\text { - Juara III Limba } \\
\text { MIPA Tingkat Gugus }\end{array}$ & $\begin{array}{l}\text { - Juara I Hasta Karya } \\
\text { Tingkat Gugus }\end{array}$ \\
\hline 6. & SDN Kopyah II & $\begin{array}{l}\text { - Juara I Lomba Siswa } \\
\text { berprestasi Tingkat } \\
\text { Kecamatan } \\
\text { - Juara I Lomba } \\
\text { Calistung Tingkat } \\
\text { Kecamatan } \\
\text { - Juara II Lomba Mipa } \\
\text { Tingkat Kecamatan }\end{array}$ & $\begin{array}{l}\text { - Juara II O2SN Cabang } \\
\text { Sepak Bola Tingkat } \\
\text { Gugus } \\
\text { - Juara I O2SN Cabang } \\
\text { Catur Tingkat Gugus }\end{array}$ \\
\hline 7. & SDN Kopyah III & $\begin{array}{l}\text { - Juara III Lomba } \\
\text { siswa berprestasi } \\
\text { tingkat kecamatan }\end{array}$ & $\begin{array}{l}\text { - Juara II O2SN Cabang } \\
\text { Atletik }\end{array}$ \\
\hline 8. & SDN Lempuyang I & 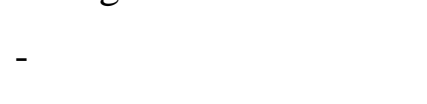 & $\begin{array}{l}\text { - Juara III O2SN Cabang } \\
\text { Catur }\end{array}$ \\
\hline 9. & SDN Lempuyang II & $\begin{array}{l}\text { - Juara II Sapta Lomba } \\
\text { PAI Tingkat } \\
\text { Kecamatan }\end{array}$ & $\begin{array}{l}\text { - Juara I. Lomba Baca } \\
\text { Tulis Al Qur'an Tingkat } \\
\text { Gugus }\end{array}$ \\
\hline
\end{tabular}

Sumber: Data capaian prestasi tertinggi siswa di SD Negeri wilayah gugus II 
Dari tabel diatas dapat diketahui bahwa hanya beberapa SD saja siswa yang dapat meraih prestasi di tingkat kecamatan apalagi sampai tingkat kabupaten.

Diperkuat dengan hasil uji kompetensi guru (UKG) Tahun 2015 hasilnya masih sangat memprihatinkan seperti tertera pada tabel dibawah ini:

Tabel 2 Hasil Uji Kompetensi Guru (UKG) Gugus II Tahun 2015

\begin{tabular}{ccccccc}
\hline \multirow{2}{*}{ No } & \multirow{2}{*}{ Nama SD } & Jml. Guru & \multicolumn{2}{c}{ Diatas Standar } & \multicolumn{2}{c}{$\begin{array}{c}\text { Dibawah } \\
\text { Standar }\end{array}$} \\
\cline { 4 - 7 } & & & Jml. & $\mathbf{\%}$ & Jml. & \% \\
\hline 1. & SDN Anjatan Baru I & 6 & 2 & 33,33 & 4 & 66,67 \\
2. & SDN Anjatan Baru II & 7 & 5 & 71,43 & 2 & 28,57 \\
3. & SDN Anjatan Baru III & 5 & 2 & 40,00 & 3 & 60,00 \\
4. & SDN Anjatan Baru IV & 7 & 1 & 14,29 & 6 & 85,71 \\
5. & SDN Kopyah I & 8 & 4 & 50,00 & 4 & 50,00 \\
6. & SDN Kopyah II & 8 & 7 & 87,50 & 1 & 12,50 \\
7. & SDN Kopyah III & 9 & 4 & 44,44 & 5 & 55,56 \\
8. & SDN Lempuyang I & 3 & 1 & 33,33 & 2 & 66,67 \\
9. & SDN Lempuyang II & 3 & 2 & 66,67 & 1 & 33,33 \\
& $\quad$ Jumlah & $\mathbf{5 6}$ & $\mathbf{2 8}$ & $\mathbf{5 0 , 0 0}$ & $\mathbf{2 8}$ & $\mathbf{5 0 , 0 0}$ \\
\hline
\end{tabular}

Sumber : hasil uji kompetensi guru Kecamatan Anjatan Tahun 2015

Tabel diatas belum termasuk guru yang belum berkesempatan mengikuti uji kompetensi guru (UKG).

Dari data diatas jelaslah bahwan tingkat kompetensi guru sebagai salah satu indikator bahwa kinerja guru SD negeri di gugus II pada UPTD Pendidikan Kecamatan Anjatan masih banyak yang belum memenuhi standar. Bagaimana mungkin guru dapat meningkatkan kempetensi siswa dan melaksanakan tugas dengan baik jika kompetensi gurunya sendiri masih dibawah standar.

Salah satu faktor penentu yang dapat meningkatkan kinerja guru adalah kepemimpinan kepala sekolah. Kepemimpinan kepala sekolah terletak pada melakukan pekerjaan memimpin. Kepemimpinan kepala sekolah pada hakikatnya adalah proses mempengaruhi seorang atau kelompok dalam usaha-usaha pencapaian tujuan (Oteng Sutisna, 2005:300). Dari definisi ini dapat diartikan bahwa kepemimpinan kepala sekolah memiliki pengaruh besar terhadap peningkatan kinerja guru, yakni mempengaruhi guru agar guru mau meningkatkan kinerjanya untuk dapat mencapai tujuan sekolah. Menurut Mulyasa (2009:98) fungsi kepala sekolah 
adalah sebagai educator (pendidik), sebagai manajer, administrator, supervisor, leader (pemimpin), innovator, dan sebagai motivator.

Disamping kepemimpinan kepala sekolah ada faktor-faktor lain yang dapat mempengaruhi kinerja guru diantaranya iklim organisasi. Iklim organisasi adalah kualitas lingkungan internal yang dialami oleh anggota-anggotanya, mempengaruhi sikap dan perilaku serta dapat tergambar dalam sejumlah nilai karakteristik khusus dari suatu organisasi dan disebut sebagai kepribadian organisasi tersebut yang merupakan pemikiran hasil persepsi dari anggota organisasi. Iklim organisasi mempengaruhi praktik dan kebijakan SDM yang diterima oleh anggota organisasi. Iklim organisasi yang terbuka memacu pegawai untuk mengutarakan kepentingan dan ketidakpuasan tanpa adanya rasa takut akan tindakan balasan dan perhatian. Ketidakpuasan seperti itu dapat ditangani dengan cara yang positif dan bijaksana. Iklim organisasi yang dapat memberi kenyamanan, otonomi, kerja sama bagi guru serta aturan-aturan yang jelas dapat meningkatkan motifasi kerja guru yang dalam akhirnya kinerja guru meningkat.

Dari uraian di atas dapat disimpulkan bahwa perlu adanya upaya untuk meningkatkan Kinerja guru oleh pihak manajemen. Sehingga guru senantiasa memiliki tingkat gairah kerja, disiplin, dan produktivitas yang tinggi. Apabila kinerja guru tinggi maka akan meningkatkan daya saing sekolah. Namun jika guru malas bekerja sehingga tidak bisa mencapai target prestasi yang diinginkan, maka sulit bagi sekolah untuk dapat memperoleh hasil yang baik dan optimal. Hal ini mengharuskan para pimpinan menggunakan kewenangannya untuk mengubah sikap dan perilaku bawahannya supaya mau bekerja dengan lebih giat serta berkeinginan untuk mencapai hasil optimal.

\section{METODE PENELITIAN}

Kerlingger (2004:483) mengungkapkan bahwa desain penelitian atau rancang bangun penelitian adalah rencana dan struktur (model/paradigma) penyelidikan yang disusun sedemikian rupa untuk memperoleh jawaban atas pertanyaan-pertanyaan penelitian. Penelitian yang dilakukan penulis menggunakan metode analisis deskriptif, yaitu penelitian terhadap masalah-masalah berupa fakta-fakta saat ini dari suatu populasi. Populasi dalam penelitian ini adalah seluruh guru sekolah dasar negeri pada gugus II UPTD Pendidikan Kecamatan Anjatan yang dengan jumlah sekolah ada Sembilan SD Negeri, dan jumlah guru ada 79 orang termasuk kepala sekolah dan guru tidak tetap (GTT).

Dalam hal ini penulis menggunakan teknik pengumpulan data studi literature/dokumentasi, observasi, dan kuesioner/ angket. Sebelum kuesioner digunakan 
untuk pengumpulan data, terlebih dahulu diuji validitasnya kepada responden dengan menggunakan korelasi Product Moment dan pengujian reliabilitas menggunakan rumus "alpha" dari Spearman Brown. Data-data yang telah diperoleh dari hasil observasi dan angket dianalisis dengan menggunakan rumus korelasi rumus regresi linier sederhana dan regresi jamak. Sebelum menguji hipotesis penelitian, terlebih dahulu dilakuka nuji persyaratan analisis yang meliputi uji normalitasmenggunakan Kolmogorow Smirnovdan uji linieritas melalui pengujian hipotesis nol.

\section{HASIL DAN PEMBAHASAN}

Jumlah responden menurut jenis kelaminsebanyak 50,63\% berjenis kelamin Laki-laki dan 49,37\% berjenis kelamin perempuan, hal ini dapat disimpulkan bahwa guru-guru SD Negeri di wilayah gugus II (Dewi Sartika) UPTD Pendidikan Kecamatan Anjatan antara jumlah laki-laki dan perempuan terbilang seimbang. Jumlah responden menurut usia yaitu dengan jumlah guru yang ada di SD Negeri di wilayah gugus II UPTD Pendidikan Kecamatan Anjatan prosentase tertinggi ada pada usia diatas 50 tahun. Bahkan sebagian diantara mereka sebanyak 5 orang sudah jelang pensiun tahun 2018.Jumlah responden menurut latar belakang pendidikan guru-guru di SD Negeri di wilayah gugus II UPTD Pendidikan Kecamatan Anjatan lebih dari $80 \%$ sudah memenuhi standar kualifikasi S1, yakni 78,48 \% S1, dan 2,53\% sudah. S2 dan untuk PNS lebih dari 85\% sudah bersertifikat profesi, untuk yang belum memenuhi standar kualifikasi S1, umumya adalah guru honorer. Jumlah responden menurut masa kerja lebih dari 50\% masih dibawah 20 tahun meski masa kerja tak mutlak menjadi tolok ukur kemampuan profesionalisme guru, namun masih banyak kesempatan untuk pengembangan diri untuk menuju profesionalisme yang lebih baik.

Dari hasil olah data angket yang disebarkan kepada 79 orang responden dangan jumlah pertanyaan yang telah diuji validitas dan reliabelitasnya yakni sebayak 21 item pertanyaan sekor variabel peran kepala sekolah adalah 6,949 dengan mean 87,96 standar deviasi sebesar 4,678 serta varian 21,883 sedangkan skor tertinggi dalam angket ini adalah 96 dan sekor terendahnya 23. Sekor ideal peran kepala sekolah 105, maka presentase variable kepemimpinan kepala sekolah adalah 83,77\% (sangat baik)sehingga dapat dinyatakan bahwa peran kepala sekolah SD Negeri pada Gugus II di UPTD Pendidikan Kecamatan Anjatan berada dalam katagori sangat baik.

Angket mengenai iklim organisasi yang disebarkan kepada 79 Responden yang berada di SD Neegeri wilayaah gugus II UPTD Pendidikan Kecamatan Anjatan dengan jumlah 20 item pertanyaan yang sudah dinyatakan valid dan reliabel setelah dilakukan uji validitas dan 
reliabelitasnya. Jumlah skor angket Iklim organisasi adalah 6.716 dengan rata-rata (mean) 85,01 standar deviasi sebesar 7,006 serta varian 49,090, sedangkan skor tertinggi dalam angket variable ini yaitu 97 dan skor terendahnya adalah 31. Skor ideal variable iklim organisasi adalah 100. Maka presentasevariable iklim organisasi adalah 85,01 \% (Sangat baik).

Sedangkan angket mengenai kinerja guru yang disebarkan kepada 79 responden yang berada di SD Neegeri wilayah gugus II UPTD Pendidikan Kecamatan Anjatan dengan jumlah 22 item pertanyaan yang sudah dinyatakan valid dan reliabel setelah dilakukan uji validitas dan reliabelitasnya. Jumlah skor angket kinerja guru adalah 7,141 dengan rata-rata (mean) 90,39 standar deviasi sebesar 6,073 serta varian 36.883, sedangkan skor tertinggi dalam angket variable ini yaitu 100 dan skor terendahnya adalah 23. Skor ideal variable kinerja guru adalah 115. Maka presentase variable kinerja guru adalah 78,6\% (baik).

Pengujian tingkat kenormalannya dengan menggunakan analisis Kolmogorow Smirnov Goodness of Fit Test dengan bantuan software computer SPPS.Berdasarkan output one sample Kolmogorow Smirnov Goodness of Fit Test, diperoleh nilai Asymp. sig (2-tailed) untuk variable peran kepala sekolah $\left(\mathrm{X}_{1}\right)$ 0,200 $=20,0 \%$ dan lebih besar dari $5 \%$ atau $(20,0 \%$ $>5 \%$, nilai Asymp. sig (2-tailed) untuk variable iklim organisasi $\left(\mathrm{X}_{2}\right)$ 0,200 = 20,00\% lebih besar dari 5\% (20,00\% > 5\%) dan nilai Asymp. sig (2-tailed) untuk variable kinerja guru (Y) $0,200=20,00 \%$ lebih besar dari $5 \%(20,00 \%>5 \%)$ maka hipotesis nol $\left(\mathrm{H}_{0}\right)$ diterima dan dengan demikian semua variable baik dependen maupun variable indevendenya berdistribusi normal.

Hasil uji linearitas variable peran kepala sekolah $\left(\mathrm{X}_{1}\right)$ atas variable Kinerja guru $(\mathrm{Y})$ sidapatkan angka signifikasi sebesar 29,2\% > 0,05 berarti linear. Sehingga data variable peran kepala sekolah $\left(\mathrm{X}_{1}\right)$ linear dengan data variable kinerja guru (Y).Hasil uji linearitas variable Iklim organisasi $\left(\mathrm{X}_{2}\right)$ atas variable Kinerja guru $(\mathrm{Y})$ sidapatkan angka signifikasi sebesar $28,4 \%>0,05$ berarti linear. Sehingga data variable Iklim organisasi $\left(\mathrm{X}_{2}\right)$ linear dengan data variable kinerja guru $(\mathrm{Y})$.

Pengujian hipotesis pertama dalam penelitian ini dapat diketahui dengan membandingkan antara nilai probabilitas 0,05 dengan nilai probabilitas pada nilai Sig pada table diatas. Karena niali Sig $(0,000<0,05)$ maka hasil $\mathrm{H}_{0}$ ditolak, dan $\mathrm{H}_{1}$ diterima, artinya terdapat pengaruh positif dan signifikan peran kepala sekolah terhadap kinerja guru-guru sekolah dasar negeri pada gugus II di UPTD Pendidikan Kecamatan Anjatan. Besarnya pengaruh variable $\mathrm{X}_{1}$ terhadap $\mathrm{Y}$ didapat bahwa $R$ Square sebesar 0,183 . Ini berarti koofesien determinasi $=\mathrm{r}^{2} \times 100 \%=0,183 \times 100 \%=18,3 \%$ artinya variabel $\mathrm{Y}$ dipengaruhi oleh 
variable $\mathrm{X}_{1}$ sebesar $18,3 \%$ dan sisanya sebesar $81,7 \%$ dipengaruhi oleh variable $\mathrm{X}_{2}$ dan variable lain yang tidak diteliti dalam penelitian ini.Besarnya pengaruh variable $X_{2}$ terhadap $\mathrm{Y}$ didapat bahwa R Square sebesar 0,288. Ini berarti koofesien determinasi $=r^{2} \times 100 \%=$ $0,288 \times 100 \%=28,8 \%$ artinya variable $\mathrm{Y}$ dipengaruhi oleh variable $\mathrm{X}_{2}$ sebesar $28,8 \%$ dan sisanya sebesar $71,2 \%$ dipengaruhi oleh variable $X_{1}$ dan variable lain yang tidak diteliti dalam penelitian ini.Besarnya pengaruh variable $\mathrm{X}_{1}$ dan $\mathrm{X}_{2}$ terhadap $\mathrm{Y}$ didapat bahwaR ${ }^{2}$ sebesar 0,344 ini memberikan arti bahwa pengaruh peran kepala sekolah $\left(\mathrm{X}_{1}\right)$ dan iklim organisasi $\left(\mathrm{X}_{2}\right)$ secara bersama-sama terhadap peningkatan kinerja guru $(\mathrm{Y})$ sebesar $34,4 \%$ sedangkan sisanya $65,6 \%$ ditentukan oleh factor lain $(\varepsilon)$ yang tidak diteliti pada penelitian ini.

Dari analisis data di atas didapat bahwa terdapat pengaruh peran kepala sekolah terhadap kinerja guru sebesar 18,3\% dengan demikian peran kepala sekolah yang efektif dalam memimpin organisasinya dalam hal ini sekolah Dasar Negeri di Gugus II UPTD Pendidikan Kecamatan Anjatan maka kinerja guru semakin meningkat. Terdapat pengaruh positip variabel iklim organisasi terhadap kinerja, yaitu sebesar $28,8 \%$. Pengaruh peran kepala sekolah terhadap kinerja guru menunjukan hasil koefisien regresi yang positif dan signifikan. Adapun pengaruh secara bersama-sama variabel peran kepala sekolah dan iklim organisasi terhadap kinerja guru sebesar $34,4 \%$.

\section{PENUTUP}

Berdasarkan hasil penelitian dan pembahasan yang telah dilakukan maka dapat diambil kesimpulan sebagai berikut:

1. Ada pengaruh positif dan signifikan peran kepala sekolah terhadap kinerja guru sebesar $18,3 \%$. Pengaruh positif ini berarti bahwa jika peran kepala sekolah semakin baik maka kinerja guru meningkat.

2. Ada pengaruh positif dan signifikan iklim organisasi terhadap kinerja guru sebesar $28,8 \%$. Pengaruh positif ini berarti bahwa jika guru semakin profesional dalam melaksanakan tugasnya maka maka kinerja guru meningkat.

3. Ada pengaruh pengaruh positif dan signifikan peran kepala sekolah dan iklim organisasi bersama-sama terhadap kinerja guru sebesar 34,4\%. Pengaruh positif ini berarti bahwa jika peran kepala sekolah dan guru semakin profesional dalam melaksanakan tugasnya maka maka kinerja guru meningkat. 
Dengan mengetahui adanya pengaruh yang positif antara peran kepala sekolah, iklim organisasi baik secara bersama-sama maupun secara parsial serta mengetahui karakteristik yang memberi pengaruh paling besar terhadap kinerja guru SD Negeri di gugus II, UPTD Pendidikan Kecamatan Anjatan Kabupaten Indramayu, maka :

1. Kepala sekolah sebagai figur sentral di sekolah yang dipimpimpinnya harus senantiasa mengupayakan dan memberdayakan guru secara terus menerus agar kinerja guru tetap baik, dan guru semangat dalam melaksanakan tugas, mengingat kinerja guru belum optimal baru sebesar 78,31\%.

2. Iklim organisasi harus tetap dijaga dan ditingkatkan, karena guru SD Negeri di gugus II UPTD Pendidikan Kecamatan Anjatan Kabupaten Indramayu masih ada yang berkategori cukup dan bahkan kurang profesional dalam melaksanakan tugasnya. Oleh karena itu guru harus mau dan membuka wawasan cara melaksanakan evaluasi pengajaran dan administrasi sekolah yang baik.

3. Bagi semua pemangku kepentingan pendidikan hendaknya turut serta dalam upaya peningkatan kinerja dan profesionalisme guru agar kinerja guru semakin meningkat.

4. Bagi Dinas Pendidikan

a. Memfasilitasi dan mendorong pihak sekolah untuk memperhatikan aspek yang dapat meningkatkan kinerja guru dalam rangka meningkatkan mutu pendidikan.

b. Memfasilitasi dan memberi dukungan pihak sekolah dalam terciptanya iklim organisasi yang kondusif.

5. Bagi Peneliti lain

Semoga laporan penelitian ini bias bermanfaat sebagai rujukan atau reverensi dalam melaksanakan penelitian lanjutan sehinga penelitian dapat membuahkana hasil yang lebih baik lagi

6. Bagi Peneliti

Hasil penelitian ini dapat digunakan ditempat peneliti bertugas nantinya.

\section{UCAPAN TERIMAKASIH}

Dalam penulisan karya ilmiah ini tidak terlepas dari bimbingan, saran dan arahan, oleh karena itu dengan penuh hormat dan terima kasih yang sebesar-besarnya kepada semua pihak yang telah membantu. 


\section{DAFTAR PUSTAKA}

Djamarah, S. B. dan Aswan Zain. (2002). Strategi Belajar Mengajar. Jakarta: Rineka Cipta.

E. Mulyasa, (2009), Menjadi Kepala Sekolah Profesional, Bandung: PT Remaja Rosdakarya.

Kerlinger, Fred. N. (2004). Asas-Asas Penelitian Behavioral. Yogyakarta: Gajah Mada University Press.

Oteng Sutisna. (2005). Administrasi Pendidikan Dasar Teoritis untuk Praktek Profesional. Bandung: Angkasa 